Sonderdruck aus

Silvio Cruschina / Katharina Hartmann / Eva-Maria Remberger (eds.)

\title{
Studies on Negation
}

Syntax, Semantics, and Variation

With 23 figures

V\&R unipress

\section{Vienna University Press}

ISSN 2365-7731

ISBN 978-3-8471-0560-2

ISBN 978-3-8470-0560-5 (E-Book)

ISBN 978-3-7370-0560-9 (V\&R eLibrary) 



\section{Contents}

Silvio Cruschina, Katharina Hartmann \& Eva-Maria Remberger

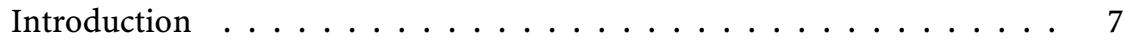

Anne Breitbarth

Jespersen's Cycle $=$ Minimize Structure + Feature Economy $\ldots \ldots \ldots 21$

Karen De Clercq

The nanosyntax of French negation: A diachronic perspective . . . . . 49

Cecilia Poletto

Negative Doubling: In favour of a "Big NegP" analysis . . . . . . . . 81

Adam Ledgeway

Marking presuppositional negation in the dialects of southern Italy $\ldots 105$

Maria Barouni

Challenging the strict vs. non-strict distinction of Negative Concord:

A syntactic proposal . . . . . . . . . . . . . . . . . . 131

Jakob Steixner

Focus Intervention and Double Negation in Bavarian $\ldots \ldots \ldots 157$

Doris Penka

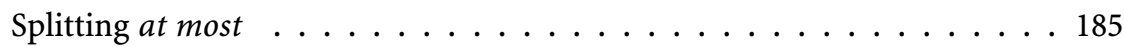

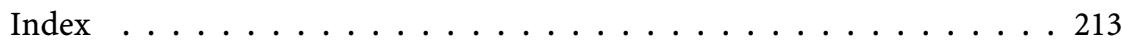





\title{
Cecilia Poletto
}

\section{Negative Doubling: In favour of a "Big NegP" analysis}

\begin{abstract}
In this work, I reformulate PoLLock's (1989) analysis of French discontinuous negation and argue in favour of a cartographic approach to the category called NegP. I propose that it is a complex category which contains at least four different projections and I will show that the various types of discontinuous negation found in several Northern Italian dialects can be analysed in the same way as DP doubling has been analysed by KAYNe (1975) and Belletti (2005), i.e. as independent movement of structural portions of an originally unitary constituent containing all negative markers first merged inside the VP. This proposal explains the numerous exceptions to ZAnUtTinI's (1997) analysis noted by MANZINI \& SAvoia (2011) without rejecting the core of her proposal. Furthermore, this view is potentially interesting in a wider perspective if we assume that each of the elements identified here expresses structural projections relevant to semantics and could ultimately lead to a different way of conceiving negation as something different from the operation of formal logic which negates propositions.
\end{abstract}

Keywords: discontinuous negation, Northern Italian dialects, DP doubling, negative concord, functional projections

\section{Introduction}

In this work, I will examine the distribution of negative markers in Italian dialects and will provide arguments in favour of an old idea that is already present in Pollock's (1989) analysis of negation in French: he proposes that the two sentential negative markers ne and pas in French originate as the head and the specifier of a single projection located in between AgrP and TP. On the other hand, subsequent work like RowletT $(1998,2007)$ has entertained the hypothesis that the negative marker pas is actually located much lower in the structure of the clause than PoLLOCK had originally proposed, in a position which can either be the one of the direct object or adjoined to the vP. A similar proposal, i. e. that 
the negative marker is first merged in the object position, is made by BAYER (2009) and MANzini \& SAvoia (2011). The view that $n e$ and pas form originally a constituent and the view that pas is actually merged lower than the position where we see it are not incompatible. If they are combined, they actually achieve more predictive power. They can explain some of the exceptions to ZANUTTINI's (1997) generalizations noted by MANZINI \& SAvoia $(2005,2011)$ with respect to the distribution of sentential negative markers in Northern Italian dialects without throwing away the whole bulk of empirical generalizations originally provided by ZANUTTINI's work. More specifically, I will propose that all negative markers occurring in languages with discontinuous negation start out as a unit, and that this unit is first merged inside the $\mathrm{vP}$, not necessarily in the object position, but definitely in an argumental one. ${ }^{1}$ Pollock's (1989) original intuition about negation and much old and recent work on doubling starting from Kayne (1975), Uriagereka (1995), Cecchetto (2000), Belletti (2005), Poletto (2008a,b), a.o., can be reinterpreted in the following way: all elements that appear to have a unitary function in the clause are first merged together. This is valid for clitic doubling of arguments, where, despite appearances, the clitic and the DP are merged as a unitary nominal expression with a single thematic role and are then independently moved to different positions, but it is also valid for negative markers when they do not give rise to double negation. This means that although we apparently see two or even three negations in the clause, there is actually only one constituent performing the function of negation. I will therefore use the term "negative doubling" with the meaning of two or more sentential negative markers which do not give rise to double negation; the term is not identical to discontinuous negation, since it also encompasses cases in which doubling is not obligatory, but adds sentence implicatures to the original negative marker related to the speaker/hearer expectations.

The paper is split according to the two conceptual steps of the argumentation: I will first present ZANUTTINI's analysis of Northern Italian negative markers and will address the exceptions to her generalizations noted by MANZINI \& SAvoiA (2011) and by GARzonio (2008), showing that her analysis is correct if complemented by the idea that all negative markers start out as a syntactic unit. In section 3, I will show that negative doubling and clitic doubling are two instances of the same phenomenon, as they share crucial syntactic properties. In section 4, I will take into account the various cases of doubling found in the Northern Italian dialects (NIDs) and show that they can all be derived by means of the cartographic approach to NegP proposed

\footnotetext{
1 An alternative would be to assume that negation takes the first argument merged as its complement, in verbs which do not have any thematic role associated to them; this could be the event itself. I will leave this possibility open, since I do not have any direct evidence that the negative marker is always located in the object position.
} 
here. Section 5 is a tentative account of a cartographic approach to negation and provides some insights into future perspectives concerning non-standard negation. Section 6 concludes the article.

\section{On the internal layering of NegP}

In order to answer the question about the number and properties of the markers involved I will first summarize ZANUTTINI's (1997) results on NIDs. She shows that inside the Northern Italian domain there are at least four types of negative markers, whose syntactic distribution varies. On the basis of the test with adverb positions in CINQUE (1999), she notices that we have to assume that there are at least four distinct positions for sentential negative markers inside the sentence structure, since they are interspersed inside the FPs in whose specifiers we see different classes of adverbs: ${ }^{2}$

a) NegP1 is the position of the preverbal negative marker of the type non, also found in standard Italian and typically found in North Eastern Italian dialects which displays typical clitic properties in all the Romance languages in which it occurs:

(1) No so. (Venice)

neg1 know

'I do not know.'

b) NegP2 is the position of negative markers of the type pas, also found in French. This type of elements is located above the adverb already marking AnteriorT in CinquE's theory of sentence structure. In this position we generally find elements that were originally minimizers, i. e. classifier-like nouns indicating a small quantity, like French pas (literally 'step'), Rhaetoromance buca 'morsel', Florentine punto 'dot', and Emilian brisa and Lombard mia (originally 'crumble').
(2) A su mia. (Bagnolo S. Vito, MN $)^{3}$
I know neg2
'I do not know.'

c) NegP3 is the position of negative markers whose etymological origin is related to the element meaning 'no-thing', like Piedmontese nen or Rhaetoromance nia, etymologically similar to the German or English negative markers.

2 I use the exact same terminology here as ZanutTini.

3 Here I use the same reference system I used in Poletro (2000) to refer back to dialects, i.e. I provide the name of the town and the abbreviation of the 'province', the territorial administrative unit used in Italy. Only the cities that are the head of a province (as for instance in (1)) are without this additional indication, because the name is the same. This will provide an idea of the geographical area where the dialect is spoken. 
(3) A sogh nèn. (Borgo S. Martino, AL)

I know neg3

'I do not know.'

d) NegP4 is the last type of negative marker and the lowest one, located in the VP space, below all adverbs and in some dialects also below arguments in sentence final position. This element etymologically corresponds to the pro-sentence negative marker.

(4) Su no. (Milan)

know neg4

'I do not know.'

Using the test on adverbs first proposed by CINQUE (1999) to determine the position of other elements in the clause, the structure ZanutTini (1997) proposes on the basis of the distribution of negative markers with respect to adverbs is the following one:

(5) $\left[_{\mathrm{NegP} 1}\right.$ non $\left[{ }_{\mathrm{TP} 1} \mathrm{~V}+_{\mathrm{Agr}}\left[_{\mathrm{NegP} 2}\right.\right.$ mica $\left[{ }_{\mathrm{TP} 2}\left[_{\mathrm{AdvP}}\right.\right.$ already] $\left[_{\mathrm{NegP} 3}\right.$ niente $\left[{ }_{\text {Asp perf }} \mathrm{V}_{\text {past part }}\left[_{\text {Asp gen/progr }}\right.\right.$ [AdvP always] [NegP4 NO]]]]]]]]

This structure is not the one for standard Italian, but the abstract representation of all possible negative markers found in NIDs. Furthermore, ZANUTTINI also discusses several properties of the various negative markers, which clearly show that they are located in different positions since they interact with elements located at different heights in the sentence structure. I will only briefly summarize them here and refer to her work for a more detailed discussion and more data.

$\mathrm{NegP} 1$ is the only type of negative marker that can block subject clitic inversion, i. e. $\mathrm{T}$ to $\mathrm{C}$ in North Eastern Italian dialects, as the following examples show: ${ }^{4}$

(6) a. *No vienlo? negl comes-he 'Isn't he coming?'
b. Magnelo mina?
eats-he neg2
'Isn't he eating?'
c. Vàste nia?
(Corvara, BZ)
go-you neg3
'Aren't you going?'
(S. Anna, VE)

All negative markers are too low to block T to C except for NegP1, hence this property singles out the preverbal negative marker.

4 This test cannot be carried out for NegP4, because in all the dialects where this negative marker occurs subject clitic inversion has been lost. 
NegP1 and in some dialects NegP2 are the two negative markers that can trigger a change in the verb morphology of the imperative in cases of a negative imperative. The suppletive form of the verb can either be an infinitival, a subjunctive or a gerund depending on the dialect, but the phenomenon is the same: NegP1 and NegP2 are the only two negative markers that can display incompatibility with a true (i.e. morphologically univocally marked) imperative form, while NegP3 and NegP4 are always compatible with true imperative in all dialects observed to this point:

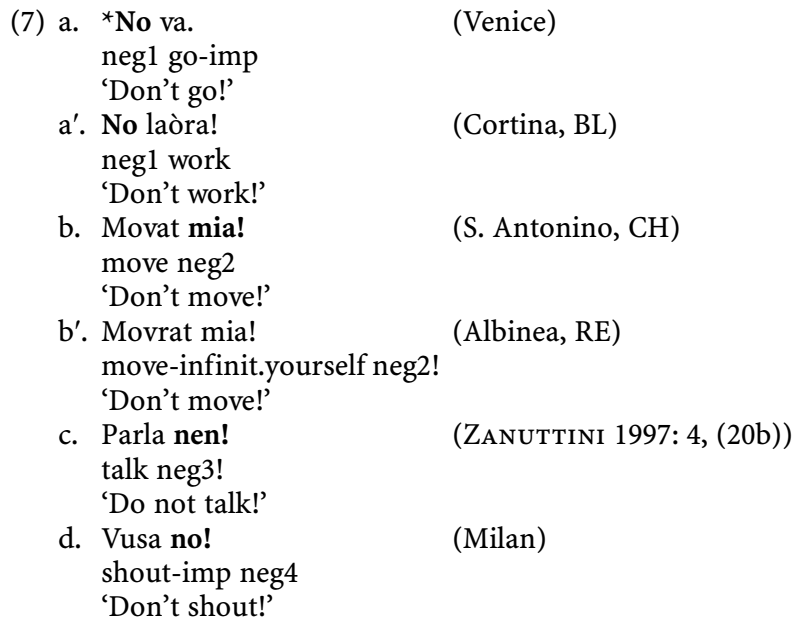

The third phenomenon that singles out different types of negative markers is the position with respect to clitics: while NegP1 is located inside the structural domain of clitics (and the ordering between them depends on the dialect), NegP2 can be the host of clitics only in those (rare) dialects which have generalized enclisis like the dialect of Borgomanero systematically investigated in TorTORA (2015). NegP3 and NegP4 never interact with clitics.

(8) a. Nol vien.

(Venice)

neg1-he comes

'He is not coming.'

b. At crumpulu opura at crumpi millu? (Borgomanero, NO)

you buy.it or you buy neg2.it

'Will you buy it or not?'

The fourth phenomenon that shows distinctions is negative concord: ${ }^{5}$ while NegP1 always requires negative concord, NegP2 frequently does not (though not

5 I make use of the standard definition of negative concord, namely those cases in which two or 
in all dialects), NegP3 does only in very limited contexts, and NegP4 has never been reported to allow for negative concord:

(9) a. No 'l è lugà nogugn.

(Cencenighe Agordino, BL)

not he is come nobody

'No one came.'

b. E'n m'a briza / mia vest endsun. $\quad(\text { Zocca, MO })^{6}$

SCL neg1 me has neg2/neg2 seen nobody

b'. E'n m'a vest entsun.

SCL neg1 me has seen nobody

'Nobody saw me.'

c. A parla nen cun gnun. he speaks neg3 with nobody

'He does not speak with anybody.'

d. L'è rivà nisun.

it is come nobody

'No one came.'

(Zocca, MO)

(Piedmontese, Zanuttini 1997: 3, (55))

(Milan)

We can summarize all these properties in the following table:

Table 1: Types of negative markers and their properties

\begin{tabular}{|l|l|l|l|l|}
\hline & NegP1 & NegP2 & NegP3 & NegP4 \\
\hline Position & preT & preAnteriorT & pregenericAsp & prevP \\
\hline V to C interference & + & - & - & - \\
\hline Negative concord & + & $+/-$ & $-/(+)$ & - \\
\hline Compatibility with true imperatives & - & $+/-$ & + & + \\
\hline Reorders with clitics & + & $-/(+)$ & - & - \\
\hline
\end{tabular}

Therefore, there are rather strong empirical arguments to believe that the four negative markers occupy different positions. However, according to ZANUTTINI's view, every element is merged in the position illustrated above in (5) without movement. In what follows, I will show that there are clear indications that negative markers do move. Furthermore, all the exceptions to (5) found by Manzini \& Savoia $(2005,2011)$ can be dealt with if we complement ZANUTTINI's proposal with the idea that all negative markers start out inside a unit located at the vP border and that (5) is the final position of the various negative markers and not the first-merge one.

more negative elements do not cancel each other out but amount to a single negation in the interpretation of the sentence.

6 The two possibilities depend on the speaker investigated. 


\subsection{Movement of negative markers}

It is well known that negative markers can move around in the clause. This was first noticed in CINQUE (1976) in his work on the postverbal negative marker mica, which can also occur (especially in Central Italian varieties) in preverbal position. In colloquial Northern Italian, we also find alternations as the following one:

(10) a. Mica ti ho detto di telefonargli. neg2 you I.have told to phone.him

b. Non ti ho mica detto di telefonargli. neg1 you I.have neg2 told to phone.him 'I did NOT tell you to phone him.'

Notice that when the postverbal negative marker is moved to the preverbal position, the preverbal one, i.e. non, disappears. This is by no means an indication that mica occupies the position of non, as all n-words in preverbal position, and the adverb mai ('never'), cannot co-occur with non when they are in preverbal position. ${ }^{7}$ Furthermore, there are clear indications that both the preverbal (cf. (11a)) and the postverbal negative marker of colloquial Italian (cf. (11b)) can occur in the CP layer in structures like the following, since the negative marker is located at the left of the complementizer:

(11) a. Non che sia stupido, è solo che non studia. neg1 that be stupid, is only that not studies

(colloquial Italian) 'He is not stupid, he just does not study enough.'

b. Mica che sia stupido, è solo che non studia. (colloquial Italian) neg2 that be stupid, is only that not studies 'He is not stupid, he just does not study enough.'

Zanuttini also notices that the Piedmontese postverbal negative marker of the NegP3 type can be found in the CP layer:

(12) par nen ch'a s stofeissa (Piedmontese) so neg3 that he himself get-tired 'in order for him not to get tired'

Therefore, these data can be perfectly handled in ZANUTTINI's approach simply by assuming that all the negative markers found in Italian varieties are not subject to any specific requirements other than those generally applied on second merge/ movement. Evidently, one has to explain why negative markers move to the $\mathrm{CP}$ domain, i.e. identify the feature that triggers the movement.

7 Since non is always analysed as a head while mica is clearly a specifier, the two elements cannot occupy exactly the same position. Evidently, it is plausible that mica goes to the specifier of the position of which non is the head. 
Further cases of movement of negative markers are provided by MANZINI \& SAvoia (2011:25-26) and reported below. They show that both negations of the $\mathrm{NegP} 3$ and of the NegP4 types can occur higher than the position where they are supposed to occur in ZANUTTINI's structure:

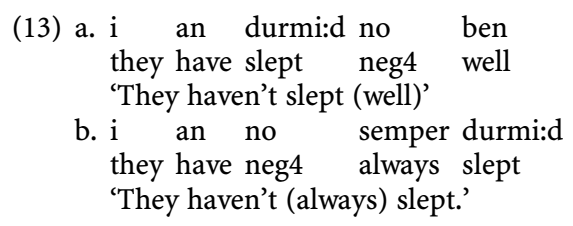

The problem for ZANUTTINI's analysis is the following: here, we have a negative marker that according to the schema in (5) should occur in the domain of the vP, i. e. lower than all adverbs, but which actually occurs higher than manner adverbs like ben 'well' and also aspectual adverbs like semper 'always'. Notice that, although ZANUTTINI does not mention any cases like these, they can still be treated in her system simply by assuming that negative markers can raise to a higher position than the one where they are merged, as must in any case be assumed for colloquial Italian preverbal mica. The only point to be cleared is once again the exact feature that triggers the movement of the negative marker to the position of a higher one, but cases like those above are in principle compatible with (5).

However, MANzini \& SAvoia $(2005,2011)$ report cases of exceptions which are more difficult to explain when starting from a structure like (5), because in their examples the negative marker occurs in a position which is lower than the first merge-position proposed by ZANUTTINI and therefore cannot be treated as an instance of movement out of the merge position illustrated in (5) as in the cases mentioned above. I only consider examples of movement of the negative marker across adverbs, and not with respect to past participle or infinitival forms, as it is well known that verbal forms can raise to different positions inside the clause in each variety (as already shown by CINQUE 1999), and this might blur the data or require a preliminary investigation of the movement span of past participle/infinitive in each dialect considered. Therefore, the respective order of verbal forms and negative markers is not safe enough as a counterargument to (5). As adverbs do not move, they are a far more reliable test.

The following Rhaetoromance case quoted by MANzinI \& SAvoia (2011) is a case of a NegP2, i.e. minimizer negation ( $b o=$ BUCCA), which occurs lower than the adverb 'yet' while according to Zanutrini's structure in (5) it is merged higher than this type of adverb:

(14) jau dormel aun bo (Münstertal)

I sleep yet neg2

'I don't sleep yet.' 
This cannot be a case of movement of the adverb, since adverbs do not generally move to other positions. ${ }^{8}$ Furthermore, it cannot be a case of constituent negation where the negative marker modifies the adverb, since constituent negation occurs on the left of the modified constituent and not on the right in NIDs. ${ }^{9}$ Hence, we are forced to conclude that this is a real exception to ZANUTTINI's analysis, which should not exist, if a system like (5) is correct. MANzInI \& SAvoia notice that the same type of data are found with NegP3, which should occur higher than the adverb 'yet', but can actually occur lower:

(15) i dormu yku naint they sleep yet neg3

'They don't yet sleep.'

Further problematic cases are those analysed in GARzonio (2008) concerning the negative marker punto in Florentine, which is once again a minimizer and should occur in NegP2, but does not, as the following data show: ${ }^{10}$

(16) Un ha ancora dormito punto (Florence)

not has yet slept neg2

'He has not slept yet.'

The fact that the negative marker occurs after the past participle is not a problem per se, since CINQUE (1999) has shown that the past participle can raise to different positions in Italian varieties. The problem here is again represented by the adverb, which does not move and is on the left of the negative marker, although it should be on the right according to (12).

Hence, if we want to keep ZANUTTINI's original generalization, which indeed has the merit of accounting for the vast majority of the data found across the

8 CINQUE's (1999) account also analyses cases of movement of adverbs to a Focus position, and cases in which adverbs are ambiguous between two readings and could therefore occur in two different positions. None of these "exceptions" apply to this example. MANzini \& Savoia mention several other cases, some of which could be seen as cases of constituent negation applying onto the adverb as the following one:

(i) El dorme no semper. (MANZini \& SAvoia 2011: 100, 27)

he sleeps not always

'He doesn't always sleep.'

They also discuss the element più in depth, though I do not deal with that here.

9 One might wonder whether this is a case of remnant movement of the FP including the vP and the adverb to the left of the negative marker, but this would imply that the order of all adverbs has to be reversed, because remnant movement of the FP should also be possible in other contexts. Since FP remnant movement is not otherwise attested, I will consider this as a real counterexample to (5).

10 Once again, this can be treated as a case of remnant movement of the FP containing ancora and dormito, but since there is no further evidence of the possibility of remnant movement in the low portion of the sentence structure and the order of the adverbs is fixed according to CINQUE's hierarchy, this is also to be considered as a real counterexample to (5). 
NIDs and at the same time explains MANZINI \& SAvoiA's exceptions, we need to complement (5) with an additional assumption, ${ }^{11}$ namely that all negative markers are merged inside a single constituent located in the $\mathrm{vP}$ area, ${ }^{12}$ as Manzini \& Savoia (2011) also assume, and then raised to the specifiers of functional positions in the clausal spine according to the standard mechanism of probe and goal (see section 5 for a first sketch of a proposal). This explains the first set of movements discussed above, where postverbal negative markers like colloquial Italian mica occur preverbally like in (10), it explains cases where any type of negative marker is found in the CP layer above the complementizer (cf. 11, 12), but also cases of negative markers which occur in a position apparently lower than the one where they are merged according to (5). Therefore, my proposal is that (5) is correct, but is to be seen as the result of second merge/movement of the negative markers in the majority of the dialects, not as the merge positions of all negative markers.

The strongest counterexamples to ZanUTTINI's schema discussed by MANZINI \& SAvoIA $(2005,2011)$ (see 13-16), i. e. cases where a given negative marker occurs lower than the position where ZANUTTINI places it in the structure, can only be explained by admitting that the negative marker remains in its original merge position. (5) has thus to be complemented in the following way:

(17) $\left[_{\mathrm{NegP} 1}\right.$ non $\left[_{\mathrm{TP} 1} \mathrm{~V}+_{\mathrm{Agr}}\left[_{\mathrm{NegP} 2}\right.\right.$ mica $\left[_{\mathrm{TP} 2}\left[_{\mathrm{AdvP}}\right.\right.$ already] $\left[_{\mathrm{NegP} 3}\right.$ niente $\left[{ }_{\mathrm{Asp} p e r f} \mathrm{~V}_{\text {past part }}\left[_{\mathrm{Asp} g e n} / \mathrm{progr}\right.\right.$ $\left[{ }_{\mathrm{AdvP}}\right.$ always] [ $\left.{ }_{\mathrm{NegP} 4} \mathrm{NO}\right]\left[_{\mathrm{vP}}\left[\mathrm{vp} \ldots\left[_{\mathrm{NegP}}[\mathrm{mica}[\right.\right.\right.$ non [niente $\left.\left.\left.\left.\left.\left.\left.\left.\left.\left.]]\right]\right]\right]\right]\right]\right]\right]\right]\right]\right]$

The assumption that negation is first merged in the VP gives us the possibility to explain doubling in a straightforward way if we assume that the "NegP" found inside the VP is the unit that contains all the negative markers in the clause before splitting in order to reach the various positions where ZANUTTINI has identified them. In what follows, I will show that the syntax of doubling also supports the view that all negative markers are merged inside a "Big NegP" located inside the VP.

11 Manzini \& SAvoia actually propose that the negative marker is a noun and is always generated as a nominal constituent inside the position of the direct object. Whether this is the only possible position is still an open question, as the negative marker might be located in different argumental positions according to the thematic structure of the verb. This is rather clear if one observes the distribution of negative indefinite articles in German, which do not only occur in the direct object position, but also on dative objects, if the verb selects a dative complement. Therefore, I will not identify a specific position inside the VP, as MANZINI \& SAvora do, what I am interested in here is the internal layering of the category called "NegP".

12 As mentioned in section 1, the idea that the sentential negative marker starts out in object position is present in RowletT's work $(1998,2007)$ on French and is proposed by BAYER (2009) for German 'nichts'. German actually shows rather clearly that the negative marker can be on the object, since it has negative indefinite articles. 


\section{Negative doubling and clitic doubling}

It is a well known fact that the arguments of the verb can occur twice in Romance, once as a DP and once as a clitic. The phenomenon was first analysed by JAEGGLI $(1982,1986)$ for Spanish, but is found with a different distribution in French, where tonic subject pronouns must be doubled by a clitic (see KAYNE 1975); in Southern Italian dialects, which display a distribution related to differential object marking similar to the one of Spanish; and in Northern Italian dialects, where different types of subjects can or must be doubled depending on the dialect (see Poletto 2000). Furthermore, North Eastern Italian dialects display an obligatory doubling of dative arguments of all sorts, including wh-items and quantifiers (CORdIN 1993). Belletti (2005) has shown that also standard Italian has doubling, not of clitics, but of tonic pronouns in emphatic structures ${ }^{13}$ and she also analyses quantifier floating as a case of doubling. There are essentially two views on the phenomenon, the first one, originally proposed by JAEGGLI, is that the clitic is a type of agreement marker and therefore does not really count as an argument. This explains doubling in languages where the clitic is always obligatory, as agreement markers are, but not those languages where the clitic appears only under some circumstances (for instance only with a subclass of nominal expressions, like with pronouns or definite DPs but no quantifiers). Furthermore, this analysis does not extend to cases where neither of the two elements involved in the doubling relation is a clitic, as in the cases mentioned by Belletti (2005). The other hypothesis on the phenomenon, which was originally proposed by KAYNe (1975), URiagereka (1995) and Belletti (2005) among others, is that the elements are merged as a unit, but can raise independently to check different features in the clausal spine. This is the analysis I have also tried to defend in Poletto (2008b) and will assume here. The same can be assumed for the negative marker, where the various elements check different features (see below section 5) of a complex adverbial, much in the same spirit of the original proposal made by PoLlock.

The major theoretical reason why cases of doubling pose a potential problem is that we have two elements which express the same thematic role and case. A similar problem arises when we have several negative markers in the clause, since they should cancel each other out, but do not. Notice that the problem already exists in cases of negative concord between the negative marker and an n-word, but in this case it is possible to assume (and has actually been proposed) that the

13 These are cases like:

(i) Gianni va lui a parlare col capo

Gianni goes him to talk to the boss

'Gianni will himself go to talk to the boss.' 
$\mathrm{n}$-word is not a negative quantifier but a negative polarity element. ${ }^{14}$ This is less plausible in the case of two negative markers; however, it has been proposed that the French preverbal negative marker $n e$ is not a real negative element anymore but a sort of polarity element (see for instance BreItBARTH 2014; cf. also BREITbARTH, this volume). This is rather difficult to assume for a language like Italian, where both non and mica can occur alone and negate a clause, but they can also occur together with no double negation effect.

Therefore, the problem we face with cases of several negative markers is similar to the one of DP-doubling; we have several elements which perform the same function in the clause. In what follows I will show that the syntactic restrictions found with negative doubling are also identical to those of DP-doubling, and I will conclude that the analysis must also be the same.

\subsection{NegP doubling has the same properties as DP doubling}

The first argument in favour of an idea that there is a clear parallel between the doubling of negative markers and doubling phenomena in nominal expressions is precisely the one mentioned above. Notice that in the Northern Italian dialects (NIDs) several negative markers can occur, we find examples with two (cf. 18) or three negations (cf. 19) and combinations of all types identified by ZANUTTINI (1997) (see below section 3 for a discussion of their properties):

14 Negative doubling between two negative markers has to be kept apart from negative concord, where the negative marker occurs with quantifiers, and from negative spread where several nwords occur together. Evidence in favour of this distinction is that the three phenomena can occur in different languages and do not overlap as we would expect if they were instances of the same process. There are languages that allow for negative concord and/or negative spreading but do not allow for negative doubling, for example Bavarian (see BIBERAUER \& Zeijlstra 2012 for an analysis that keeps negative concord and negative spread distinct).

(i) a. daß da Hons koa Buach (nit) glesn hot (Bavarian)

that the Hans no book(acc) not read has

'that Hans did not read any book'

b. daß da Hons koan Freind (nit) ghoifn hot that the Hans no friend(dat) not helped has 'that Hans did not help any friend'

c. daß eam koa Mensch (nit) gseng hot that him no man(nom) not seen has 'that nobody saw him'

Here I propose that only negative doubling is to be dealt with like DP doubling, while negative concord and negative spread are instances of a different phenomenon, namely Agree (see ZeijLstra 2004). 
(18) a. Nol me piaze. (Venice) neg1-it me likes

b. Nol me piaze miga. NegP1 + NegP2 neg1-it me likes neg2

c. Nol me piaze gninte. NegP1 + NegP3 neg1-it me likes neg3

d. Nol me piaze NO. NegP1 + NegP4 neg1-it me likes neg4 'I do not like it.'

(19) No la go miga magnada NO! Neg1 it have not eaten neg4 'I did not eat it!'

These data show that it is not very plausible to assume that only one of the negative markers is the "real" negation and all the others are polarity items, since each negative marker can occur alone and negate the clause, as shown by (20):

(20) a. No!

$\mathrm{Neg} 4$

(Venice)

'No!'

b. Nol lo ga fato.

Neg1-he it has done

'He did not do it.'

c. Miga che el lo gabia fato.

Neg2 that he it has done

'He did not do it.'

In (19) we see three negative markers, the preverbal no (pronounced with a closed /o/), the postverbal negative marker miga (akin to standard Italian mica, although it occurs in more contexts than it does in standard Italian) and the pro-sentence negator no at the end of the clause (pronounced with an open $o / \mathrm{J} /$ ). Both the preverbal and the postverbal negative markers can negate the clause alone, as the pro-sentence negative marker must also be assumed to be a negation. This means that negative doubling behaves like the cases of clitic doubling noted by BELLETTI (2005), where neither element can be analysed as "something else" and therefore, the only plausible analysis is to say that they start out as a unit which is then split in the course of the derivation to check different features both belonging to the original unit but specified onto the two (or three) elements. In the next sections, I will provide further arguments to show that DP doubling and negative doubling are amenable to the same analysis and, in section 5, I will make a first proposal that can account for the features that are checked by different elements. 


\subsection{Clause bound phenomenon}

It is a well known fact that DP doubling is a clause bound phenomenon; with welldefined exceptions, we cannot double a constituent belonging to a different clause. ${ }^{15}$ The same is true of negation: it is not possible to double a negative marker with another sitting in a different clause. If we do so, the result is either ungrammaticality or a real double negation reading.

(21) a. Non mi ha detto che ${ }^{\star}$ (non) viene mica. (Italian) neg1 to.me has said that not comes neg2

b. Un m'ha detto che ${ }^{\star}$ (un) viene punto. (Florence) neg1 to.me has said that neg1 comes neg2 'He has not said that he is not coming.'

c. No credo che ${ }^{\star}$ (no) el venia NO. (Venice) neg1 (I) think that neg1 he comes neg4 'I do not think that he is not coming'

d. Nol me ga dito che ${ }^{\star}$ (no) el dorme gninte. (Venice) neg1-he has said that neg1 he sleeps neg3 'He hasn't told me that he doesn't sleep.'

(22) Non è che *(non) viene mica. (Italian) neg1 is that neg1 comes neg2

'It is not the case that he is not coming.'

If we assume that negative doubling is the result of the split of a unit containing the two (or three) negative markers, this is the expected result.

\subsection{Constituent negation}

One further rather strong argument to analyse negation doubling as originating from a single constituent (much as DP doubling in BeLletTr's 2005 analysis) is the fact that two negative elements can actually be observed to occur as a single constituent, for instance in dialects like Paduan, where constituent negation can be marked by two negative markers together (i.e. no and miga).

15 What I mean here by clitic doubling are cases in which a clitic doubles an XP in its argumental position as, for example, in Spanish. I abstract here from cases of topics, which are not analysed as real cases of movement by all authors (see for instance CINQUE 1990), from cases of wh-movement in varieties which also double wh-items through a clitic, since wh-movement is recursive, and from cases of restructuring, where the clitic sits on the modal and not on the infinitival verb, which have convincingly been analysed by CinQue (2006) as monoclausal constructions. Notice that in Italian (as well as in English) there is a phenomenon known as negation raising, which closely parallels clitic climbing. 


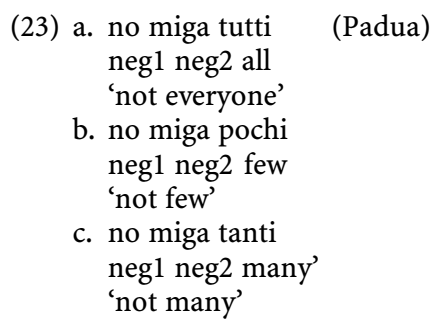

This clearly shows that the two negative markers can at least occur as a constituent, and crucially do so when the structure does not provide any clausal projection the two elements can move to.

MANZINI \& SAVOIA (2011) also report cases of two adjacent negative markers inside clauses. Data of this type are interesting for two main reasons: they show that two negative markers can occur together, and the order of the two negative markers is the opposite of the one we would expect, as the element non, which is usually found in a preverbal position comes after the negative marker mia and not in front of it:

(24) El ciami mia non anmo.

(Sant'Angelo Lodigiano, MI; Manzini \& Savoia 2011: 27)

him I-call neg2 neg1 yet

'I am not calling him yet.'

It is not self-evident that in this case the two negative markers have to be analysed as still being a unit; it could be the case that they occur in adjacent positions simply because their target positions are. However, cases like this are to be analysed, the fact that something like (24) is possible clearly shows that at least two negative markers can occur as a unit in NIDs.

On the basis of the three arguments mentioned above, I conclude that negative doubling displays properties similar to those of DP doubling and as such can potentially be analysed in the same way.

\section{Possible combinations between negative markers}

If all negative markers start out inside the vP and are then raised to a different position, as I claim here, this means that all combinations between all negative markers should be allowed. In the majority of the dialects doubling or tripling has semantic/pragmatic import in the sense that in addition to negation, it expresses the speaker's attitude towards the event not taking place or is related to an additional conversational implicature (see Cinque 1976 for an analysis of postverbal mica in colloquial Italian). However, there are also dialects where the 
combination of two negative markers does not give rise to any special reading (as it is the case of standard French). ${ }^{16}$ As seen above in section 3, in Veneto NegP1 can be combined with all other types of negative markers. The combination of NegP1 and NegP2, similar to French, is attested in the Emilian area, rather in the central part of Northern Italy.

(25) A n magn menga la cherna. (Carpi, MO)

SCL neg1 eat neg2 the meat

'I do not eat meat.'

The combination between NegP1 and NegP3 is attested in the Rhaetoromance area (in the Badia valley).

(26) Dytaurela n el nia gny.

(S. Leonardo di Badia, BZ)

yet neg1 is-he neg3 come

'He has not come yet.'

The combination between preverbal negation and $\mathrm{NegP} 4$ is attested in the Trentino area (although this type of negation goes back to a system where only preverbal negation is found, or focus negation is only used in special contexts), and is known to have existed in Milanese in the XVI century (see VAI 1996), which has nowadays only NegP4.

(27) No se dis cosi no. (Val di Non, TN)

neg1 it says so neg4

'We do not say so.'

As far as I know, there are no dialects where it is possible to combine NegP2 and $\mathrm{NegP} 3, \mathrm{NegP} 2$ and NegP4 or NegP3 and NegP4 without involving any special semantics (i.e. without giving rise to non-standard negation). ${ }^{17}$ This might be due to a historical accident, as all dialects started out with a "high" type of negation, or it might be a meaningful hole in the paradigm. With the data base used here, it

16 The geographical distribution of standard negation (i. e. non presuppositional negation) is as follows: In the Eastern Area standard negation is provided by a preverbal negative marker of the no(n) type. This area includes Veneto, Friuli, Trentino and partly Romagnolo, and the Rhaetoromance dialects of the Fassa Valley and Cortina. In the Western area standard negation is provided by a postverbal negative marker of different types (in Lombard Focus negation, in Piedmont quantifier negation) except for the Ligurian area which patterns with the East. Emilian dialects display doubling negation with a combination of scalar and minimizer negation of the standard French type, which is also a stage attested in all dialects which nowadays have postverbal negation, and this incidentally confirms Jespersen's cycle. Some Rhaetoromance dialects (Badia and Gardena) also display discontinuous negation but of the type scalar+ quantifier negation type. Hence, there is no real homogeneous trend from East to West, although this is the rough situation at first sight.

17 Each type of negative marker can give rise to different types of sentence implicatures related to the expectations of the speaker or of the hearer. The matter is too complex to be handled here. 
is not possible to make a choice between these two options, because other language types should be taken into account. ${ }^{18}$

However, the combinations which are not found for standard negation are all attested in different dialects when a special attitude of the speaker is signalled, which I will refer to as "non-standard negation". 19

Although it is not attested as standard negation, the combination between NegP2 and NegP3 is by no means impossible in other dialects. In Piedmontese, where NegP3 is the standard negative marker, the combination with NegP2 is indeed possible, so there is no a priori ban against this combination, it just depends on the implicature they are associated with in the relevant dialect.

(28) Fa pa nen sulì. (ZANutTini 1997: 46)

do neg2 neg3 that

'Don't do that.'

As mentioned in section 3, tripling exists, and is obtained either by the combination of NegP1, NegP2 and NegP4 or by NegP1, NegP3 and NegP4:

(29) a. No la go miga magnada NO!

neg1 it have neg2 eaten neg4

'I did not eat it!'

b. No-l me piaze gninte NO!

neg1-it me likes neg3 neg4

'I do not like it at all!'

The conclusion we can draw is that any type of negative marker is compatible with any other depending on the dialect. In some cases the combination gives rise to standard negation, in others to non-standard negation (see below for an analysis of the difference between standard and non-standard negation). This means that the Big NegP must contain at least four distinct projections where each of the four negative markers is sitting. ${ }^{20}$

18 For instance some Dutch dialects display the occurrence of what seems to be quantified and focus negation as standard negation. Therefore, the lack in the paradigm would be accidental and due to the fact that we are looking at languages which are all undergoing a similar diachronic process.

19 I will make use of the distinction between standard negation and non-standard negation, referring by the latter to those negative markers that can only occur under certain pragmatic conditions related to the speaker's or addressee's expectations.

20 However, it is possible that there are more than four, the typological literature on negation reports several languages which use up to three negations (see ALSENOY \& VAN DER AUWERA 2014), and some rare cases of four negative markers. JOHAN VAN DER AUWERA (p.c.) tells me that there even exist cases of five negative markers, a language that has this phenomenon is Kiranti. I will not entertain a systematic comparison with typological work on negation here, but it is clear that macro- and microvariation should complement each other when it comes to a detailed analysis of the type of projections located inside the Big NegP. 
If negative doubling is an instance of a process of splitting a unit due to independent feature checking of several features, one might ask how many and what type of positions the unit which we refer to as NegP contains. In this work, I determined how many positions there are and the elements that belong to these four categories while leaving the exact semantic value of these positions to future work, since it requires detailed semantic tests.

Nonetheless, it is possible to make some preliminary remarks concerning the approximate semantic value of the elements contained in the Big NegP, since the etymology of the negative markers is rather transparent. The two clearest cases are those of Neg2 and Neg3, the first always derives from a classifier-like element representing a minimizer, which provides the smallest quantity on a scale. NegP3 is clearly the n-word meaning 'nothing', which contains, in addition to an nmorpheme another type of light noun, the word meaning 'thing', as English also transparently shows. This element can be interpreted as an existential light noun which can be found in the nominal spine of several polarity items like 'everything', 'something' or 'anything' (see Garzonio \& Poletto 2015 on existential elements inside quantifiers in the Southern Italian dialects). As for NegP4, this seems to be related to Focus structures, since the element no occurs in the first contexts when negation is focused (see Poletro 2008a). The hardest element to identify in terms of its semantic contribution is precisely the preverbal negative marker non, which derives from 'non-unum', but was already one single word in Latin. The presence of these elements in the Big NegP might indicate that the way negation is achieved in natural language is not the way that has been supposed up to now, namely the same as the one of formal logic. It might be the case that natural languages do not simply use something like ' $\neg \mathrm{P}$ ' to negate a clause, but that the process of negation involves various steps, each of which corresponds to a distinct semantic operation and is represented by one of the four negative markers ZANUTTINi (1997) originally identified in the NIDs.

The fact that an existential, as well as a scalar minimizer and a Focus element can all be used to represent part (in cases of doubling) or the whole (in cases of singleton negation) of the "Big NegP" could simply be seen as the result of a historical process of grammaticalization, but I think that it might be interesting to pursue the alternative line of thought that what we see is a synchronic process which reflects the way in which negation is achieved in the semantics of natural languages. In the following section, I will try to sketch a formalization of the observations made until now. 


\section{The internal structure of NegP}

If it is true that natural languages do not have a single operator in their inventory which corresponds to the ' $\neg \mathrm{P}$ ' negation of a proposition of formal logic, one wonders how negation is achieved. My intention here is not to provide a definitive and reliable system of what the semantic operations that are performed to obtain negation really are, but to show how this could be done and concentrate on the syntactic aspects of such a hypothesis. Therefore, in this section I will provide a very tentative analysis of the internal projections located in the NegP; although this proposal has to be further refined or maybe even completely restated from the semantic point of view, a first approximation is nonetheless interesting to give an idea of the way the syntactic mechanism works which also allows us to make more precise syntactic predictions.

I propose that the lowest element inside NegP is an existential element. This is rather clear in those varieties that use the n-word meaning 'nothing', where one of the two formatives is clearly an existential one, as a standard negative marker. Similar existential elements are also present inside the etymological source of the Germanic negative marker originating German 'nicht', English 'not' and Scandinavian 'ikke', which all contain an existential light noun originally meaning 'body'. This is also the case of Piedmontese varieties which use the element nen derived from nent (i. e. 'nothing') which most probably contains the element ente, 'thing' or gente 'people', or of Provençal varieties using ren (the counterpart of French rien, from Latin RES once again 'thing') or of Central Ladin varieties which use nia both for the negative marker as well as for the n-word 'nothing'. On top of this existential element there must be a projection which morpho-syntactically encodes the fact that this existential is set on a scale. Although I do not have any real evidence for this, I will assume that this is the position of the preverbal negative marker non of standard Italian, Central and Southern Italian dialects as well as North-Eastern Italian dialects. The third element found in the internal structure of the NegP is a minimizer, i.e. what ZANutTini calls NegP2, and is the type of French pas, Emilian brisa, Lombard mia/minga, Veneto mia/ mina/miga, Northern Lombard bo, Florentine punto etc. This element lexicalizes the semantic operation that connects the existential to the scale, i. e. it shows that the element to be taken into consideration is the smallest one of the scale. The last element is an element that lexicalizes an operation similar to the one of Focus, i.e. it univocally identifies an element inside a set of elements with the same property. Suppose that the set in question is the set of the true propositions, then identifying one proposition and taking it out of the set amounts to negating it. Notice that there are again etymological clues of this fact since several negative markers are etymologically related to prepositions meaning 'out' (see SANFELICI 2012). What negation does in other words is to assert that something exists, and that it is 
the minimal entity on a scale and then takes it out of the set of true propositions. The set of FPs will thus be something like:

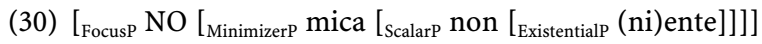

Even though in many languages the whole NegP is represented by only one of these elements, there are languages that have two or three even in cases of standard negation. Devos et AL. (2010) investigate the Jespersen cycle in the Bantu languages and mention languages which have two or three negative markers like the following one:

(31) (mvûl) kà-nák-ááy-áp (kwénd) (Kanincin, Devos ET AL. 2010: 7)

(1.rain) neg1.1sc-rain-tam-neg2 (neg3)

'it does not rain'

Furthermore, they notice that there exist cases of three negative markers which are only interpreted as standard negation (i.e. negation without any special sentence implicature) like the following:

(32) ka-zeby-áandi khúumbu ya ygúdy-áani kó

(Suundi, BAKA 1998: fieldnotes) neg1.1sc-know-neg3 9.name 9.conn 1.mother-poss.1sg neg2

'he does not know the name of my mother'

Interestingly, Devos ET AL. (2010) also discuss the probable etymological source of the possible negative markers in Bantu and reach the conclusion that one (the element $p(a)$ in (31), which for phonological reasons appears as -áp in the example) was originally a minimizer. Other elements like kwend in (31) and ko in (32) in this language group are originally elements expressing a (non-negative) Focus feature, which lends support to the idea that one of the semantic operations performed to obtain negation is the same that is also performed with Focus. This seems to indicate that the etymological sources of the elements marking negation are limited and all have to do with one of the projections sketched above. This is actually a straightforward way to explain the Jespersen cycle: given that negation is not a single projection but a set of projections expressing the basic semantic components of what results as a sentential negation, it is clear that languages can choose between elements that lexicalize one of the four projections, and that in some cases, they can even lexicalize two, three or even all four of them. Even though the semantics of (30) is most probably not correct, the syntactic idea of a set of projections can still be correct. This idea also explains why the negative markers of different etymological origins end up in different positions: they move to the position where they check the feature corresponding to their semantics: elements like Milanese no move to a Focus position (probably the one at the $\mathrm{vP}$ border, which was first identified by BELLETTI 1999) and are therefore located at the $\mathrm{vP}$ border. Elements like minimizers move 
to an aspectual position related to their meaning, i.e. probably inchoative or prospective Aspect. Elements like Piedmontese nen occupy the same position bare quantifiers occupy in French (actually the position of nen is exactly the same position as French argumental rien), elements like standard Italian non and French ne are clitics, and they move to a position inside the clitic field.

Let us now briefly see how it is possible to model non-standard negation, i.e. negative markers that are apparently optional but actually negate a conversational implicature as is the case of colloquial Italian mica already analysed as a "presuppositional negative marker" in Cinque (1976). In other words, what is the structural difference between French pas and Italian mica, if both are sitting in the same minimizer projection inside the complex NegP? I propose that the distinction is purely syntactic. In Italian the element mica is extracted from its original position inside the NegP at the $\mathrm{vP}$ edge and moved to a position in the Aspectual field which can be interpreted as marking some type of Aspect which is in a sense similar to a minimizer (probably something like inchoative). The element non, which is a clitic, moves to the clitic field as a remnant, ${ }^{21}$ with all the rest of the projections included inside NegP. This means that mica still retains its original meaning as a minimizer and the sentence implicature is computed on this basis.

French does the opposite: $n e$ is extracted out of the NegP and moved alone to the clitic field, while the whole NegP moves with pas to the Aspectual position. This means that, although pas moves to the same position as mica, it does not maintain the same value, since it is embedded under all the projections of the NegP. This explicitly formalizes the idea that pas is indeed the standard negative marker of French. In other words, the proposal I put forth is that the difference between standard and non-standard negation has to do with the amount of pied piping the various elements in the NegP drag along: if the whole NegP is dragged along, the negative marker is interpreted as standard negation, if not, only its original meaning is still accessible and the type of non standard negation is related to it.

\section{Concluding remarks}

In this work I have discussed empirical evidence in favour of the idea that discontinuous negation is to be analysed in the same way in which DP-doubling has been analysed, i.e. as the result of the split of a single unit which is first merged in a very low position inside the VP. This view allows us to account for the cases of doubling and tripling of the negative marker and the fact that all combinations are possible and actually attested. Furthermore, this view allows us to explain the

21 See Cattaneo (2009) for the proposal that all clitics are instances of remnant movement of a whole DP. 
exceptions to ZANUTTINI's hierarchy of negative markers discussed in the literature by MANZINI \& SAvoia and by Garzonio. Hence, we can keep ZANUTTINI's original proposal about the existence of four different types of negative markers, if we assume that the positions observed are the final positions and not those where the negative markers are first merged. All negative markers can be moved to different positions inside the clausal spine for feature checking starting from the unique basic position inside the vP.

\section{References}

Van Alsenoy Lauren \& Johan van der Auwera (2014): On the relation between double clausal negation and negative concord. In Hansen, Maj-Britt MosegaArd \& JaCQUeline Visconti (eds.): The Diachrony of Negation. Amsterdam: John Benjamins, $13-46$.

BAKA, JEAN (1998): Questionnaire kisuundi (complété). Unpublished.

BAYer, Josef (2009): Nominal negative quantifiers as adjuncts. The Journal of Comparative Germanic Linguistics 12: 5-30.

Belletti, Adriana (1999): "Inversion" as focalization and related questions. Catalan Working Papers in Linguistics 7: 9-45.

Belletti, Adriana (2005): Extended doubling and the VP periphery. Probus 17: 1-35.

Biberauer, Theresa \& Hedde Zeijlstra (2012): Afrikaans Negation: filling the typological gap. Journal of Semantics 29: 345-371.

Breitbarth, Anne (2014): The History of Low German Negation. Oxford: Oxford University Press.

Cattaneo, Andrea (2009): It Is All About Clitics: The Case of a Northern Italian Dialect Like Bellinzonese. $\mathrm{PhD}$ thesis, New York University.

Cecchetto, Carlo (2000): Doubling Structures and Reconstruction. Probus 12: 93-126.

Cinque, Guglielmo (1976): Mica. Annali della Facoltà di Lettere e Filosofia dell'Università di Padova 1: 101-112.

Cinque, Guglielmo (1990): Types of A'-Dependencies. Cambridge (MA): MIT Press.

Cinque, Guglielmo (1999): Adverbs and Functional Heads. Oxford/New York: Oxford University Press.

Cinque, Guglielmo (2006): Complement and Adverbial PPs: Implications for Clause Structure. In Cinque, Guglielmo: Restructuring and Functional Heads. The Cartography of Syntactic Structures. 4th vol. New York/Oxford: Oxford University Press, 11-64.

Cordin, Patrizia (1993): Dative Clitics and Doubling in Trentino. In Belletti, Adriana (ed.): Syntactic Theory and the Dialects of Italy. Turin: Rosenberg and Sellier, 130-154.

Devos, Maud, Michael Kasombo Tshibanda \& Johan van Der Auwera (2010): Jespersen cycles in Kanincin: Double, triple and maybe even quadruple negation. Africana Linguistica 16: 5-31.

Garzonio, Jacopo (2008): A case of incomplete Jespersen's cycle in Romance. Rivista di Grammatica Generativa 33: 117-135. 
Garzonio, Jacopo \& Cecilia Poletto (2015): How bare are bare quantifiers? Some notes from diachronic and synchronic variation in Italian. To appear in Linguistic Variation. Jaeggli, Osvaldo A. (1982): Topics in Romance syntax. Dordrecht: Foris.

JAEgGLI, Osvaldo A (1986): Three issues in the theory of clitics: case, doubled NPs, and extraction. In BORER, HAGIT (ed.): Syntax and semantics 19: The syntax of pronominal clitics. New York: Academic Press, 15-42.

Kayne, Richards. (1975): French Syntax. Cambridge, Mass.: MIT Press.

Manzini, Maria R. \& Leonardo M. Savoia (2005): I dialetti italiani e romanci. Morfosintassi generativa. 3rd vol. Alessandria: Edizioni dell'Orso.

Manzini, Maria R. \& Leonardo M. Savoia (2011): Grammatical Categories: Variation in Romance Languages. Cambridge: Cambridge University Press.

Poletto, Cecilia (2000): The Higher Functional Field: Evidence from Northern Italian dialects. Oxford/New York: Oxford University Press.

Poletto, Cecilia (2008a): On negative doubling. Quaderni di lavoro ASIT 8: 57-84.

Poletto, Cecilia (2008b): Doubling as a spare movement strategy. In Barbiers, Sjef, Olaf Koeneman, Marika lekakou \& Margreet van der Ham (eds.): Microvariation in Syntactic Doubling. Bingley: Emerald, 38-68.

Pollock, JeAn-Yves (1989): Verb Movement, Universal Grammar and the Structure of IP. Linguistic Inquiry 20: 365-424.

Rowlett, Paul (1998): Sentential Negation in French. Oxford: Oxford University Press.

Rowlett, Paul (2007): The Syntax of French. Cambridge: Cambridge University Press.

Tortora, Christina (2015): A comparative Grammar of Borgomanerese. Oxford: Oxford University Press.

Sanfelici, Emanuela (2012): The grammaticalization of cen in Irish: A diachronic study. Paper presented at the 26th Irish Conference of Medievalists. University College Dublin, July 5-7 2012.

Uriagereka, Juan (1995): Aspects in the Syntax of Clitic Placement in Western Romance. Linguistic Inquiry 26: 79-123.

VAI, Massimo (1996): Per una storia della negazione in Milanese in comparazione con altre varietà altoitaliane. ACME 40: 57-98.

Zanuttini, Raffaella (1997): Negation and Clausal Structure: A Comparative Study of Romance Languages. Oxford/New York: Oxford University Press.

Zeijlstra, Hedde (2004): Sentential Negation and Negative Concord. PhD thesis, University of Amsterdam. Utrecht: LOT Publications. 
